\title{
DPF retrofit program in Israel - effects of diesel particle filters on performance of in-use buses
}

\begin{abstract}
A long service life of heavy-duty diesel vehicles results in a large number of older-technology trucks and buses of various types running on roads nowadays. Cleaning up exhaust gases of these older vehicles gives an opportunity to improve air quality at affordable costs. Retrofitting older buses with diesel particulate filters $(D P F)$ is a cost-effective measure to quickly and efficiently reduce particulate matter (PM) emissions and contribute to mitigation of air pollution in urban conglomerates.

In this paper, the milestones on a way to wide-scale retrofitting of heavy-duty vehicles with DPF are discussed on the example of Israel DPF retrofit program. Crucial importance of a balanced governmental approach combining regulation and economic incentives, together with collaboration of government, academia and vehicle operators, is underlined. Main results of the one-year pilot project focused on urban and intercity buses are discussed. Impact of DPF retrofitting on particulate emissions and engine performance and maintenance aspects of in-use diesel buses is analyzed. Very high particle filtration efficiency (in average, about 97\%) together with relatively low fuel economy penalty (0.6-1.8\%, depending on the bus type) are proved. Vital importance of careful monitoring and correct maintenance of DPF-equipped vehicles is underlined.
\end{abstract}

Key words: particle emissions; diesel particle filter; heavy-duty vehicles; DPF retrofit

\section{Introduction}

Climate change challenges require substantial improvement of vehicles' energy efficiency. However, this improvement must be achieved without compromising a continuous quest to zero-impact emissions [1]. It is wellknown that combustion-generated particles formed in large quantities in diesel engines are of major concern to human health $[2,3]$. In 2012, World Health Organization officially recognized diesel-originated particles as a most dangerous carcinogenic substance (group 1) like asbestos [4]. The published scientific data provide an evidence that ultrafine particles (UFP) are more harmful to human health than larger ones because UFP penetrate cell membranes and are transferred with the blood stream to all human organs, like brain, liver, etc. [5-7].

In the effort to mitigate PM emissions from the transportation sector, several aftertreatment technologies have been proposed and developed, while the most efficient of them has been shown to be a DPF [8]. Due to the relative simplicity of installing this device on in-use vehicles, massive DPF retrofit is performed worldwide, especially in heavy-duty trucks and buses, which can be kept in service for more than 15 years [9]. DPF retrofit has reportedly led to great PM reduction, up to $99 \%$ or even more $[10,11]$.

This paper reports on the main findings and lessons of DPF Retrofit Program in Israel with a main focus on the required interaction of scientific efforts and governmental willingness to make a change, and effects of diesel particle filters on real-world performance of in-use buses

\section{Methodology}

Despite a great number of successful examples of DPF retrofit in heavy-duty vehicles, decision makers always prefer to have a positive evidence at the local scene, thus making necessary and very important a pilot test carried out in the typical for a considered case conditions and with the vehicle models representative for a considered fleet. For this reason, a pilot test with 18 in-use urban and intercity buses was carried out during a period of 12 months to pave a road for the wide-scale DPF retrofit of heavy-duty vehicles in Israel. All relevant topography conditions were covered in the test, to provide the decision makers with as much as possible information.

There is a large variety of DPF types and technologies, with different characteristics, which could be installed in buses. To choose the DPF technology most suitable for retrofitting in the tested buses, exhaust gas temperature profiles have been measured during real-world operating conditions of intercity and urban buses. For this purpose, thermocouples were installed in the exhaust manifold, before the bus silencer, of the selected buses of the pilot group. The temperature was monitored for a couple of months prior the installation of the DPF.

A typical example of the measured temperature profile is shown in Figure 1. The horizontal axis in the Figure shows temperature ranges, and the vertical axis shows the percentage of time the exhaust gases were found to lie under each designated temperature range.

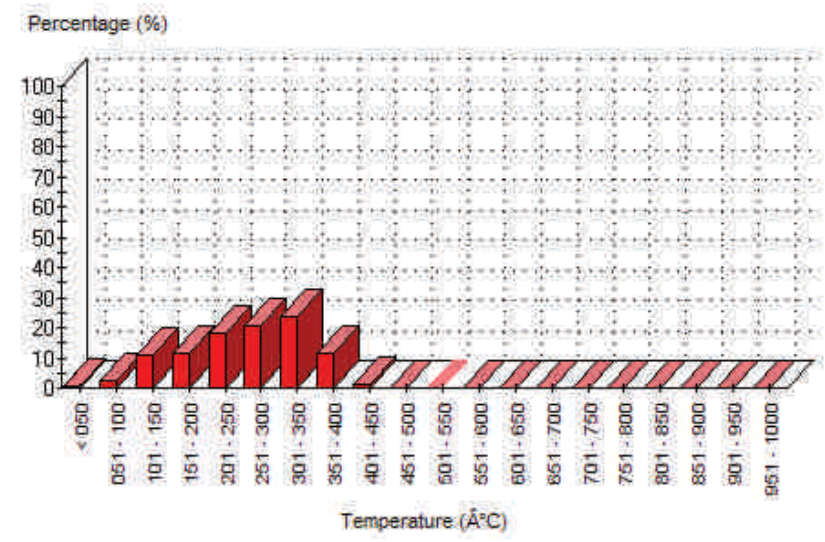

Fig. 1. Exhaust gas temperature profile of an intercity bus (in degrees Celsius) 
As can be seen, the exhaust gas temperature of the considered in-use buses was higher than $100^{\circ} \mathrm{C}, 200^{\circ} \mathrm{C}, 300^{\circ} \mathrm{C}$ and $400^{\circ} \mathrm{C}$ during $97 \%, 75 \%, 36 \%$ and $1 \%$ of total usage time, respectively. The mean temperature during engine operation was found to be $258^{\circ} \mathrm{C}$. The most suitable regeneration mechanism for this temperature profile is the NO2based soot oxidation implemented in the Continuous $\mathrm{Re}$ generation Trap (CRT) technology, developed for the first time by Johnson Matthey [12, 13]. Based on the obtained temperature profiles, three different DPF types (all of CRT technology) were selected in a close cooperation with VERT from the VERT-list of Best Available Technology (BAT) filters.

The buses (both urban and intercity) of the most popular in the local fleet manufacturers (in case of Israel - MAN and Mercedes) were selected for the pilot test. All the vehicles were produced under the Euro III emission standards, and had travelled a distance compatible with their age. Every vehicle had an original engine and had been appropriately maintained before and during the experiments.

UFP measurements were performed three times with each bus of the pilot group during the 12-months period after DPF retrofit. The measurements were carried out using the TSI-made Engine Exhaust Particle Sizer (EEPS) Spectrometer 3090 model. To assess particle number filtration efficiency PNFE, particle number concentrations (PNC) were measured upstream and downstream the DPF for each bus.

To evaluate DPF influence on the buses fuel economy, an additional group of buses of the same type and age running in the similar conditions was identified and designated as a control group. Fuel consumption data were gained for the period of 31 months for all 36 considered buses (18 of the control group and 18 of the pilot group). The data on fuel consumption before DPF retrofit allow us to estimate fuel economy deterioration due to natural aging. The data on fuel consumption of buses after DPF retrofit made possible assessment of fuel economy deterioration due to joint influence of aging and DPF itself. Knowing both number enables assessment of a sole DPF effect on fuel economy.

During the whole pilot duration, backpressure behavior in each retrofitted bus and maintenance operations were carefully monitored.

\section{Results and discussion}

The obtained results confirm known data on extremely high particle number filtration efficiency of DPFs. The averaged values of PNFE as were measured at different operation modes are shown in Fig. 2. As can be seen, PNFE of about $97 \%$ was measured at all engine operating regimes excluding low idle. The latter is not recommended for PNFE assessment due to substantially lower engine operation stability at this operation mode. The lower PNFE values at low idle are the result of higher particle agglomeration because of longer residence times due to low gas flow rates.

Figure 3 presents a histogram of the PNFE values obtained. Blue rectangles express the number of times that a result was obtained between a specific interval. The orange line expresses the cumulative percentage of measures.

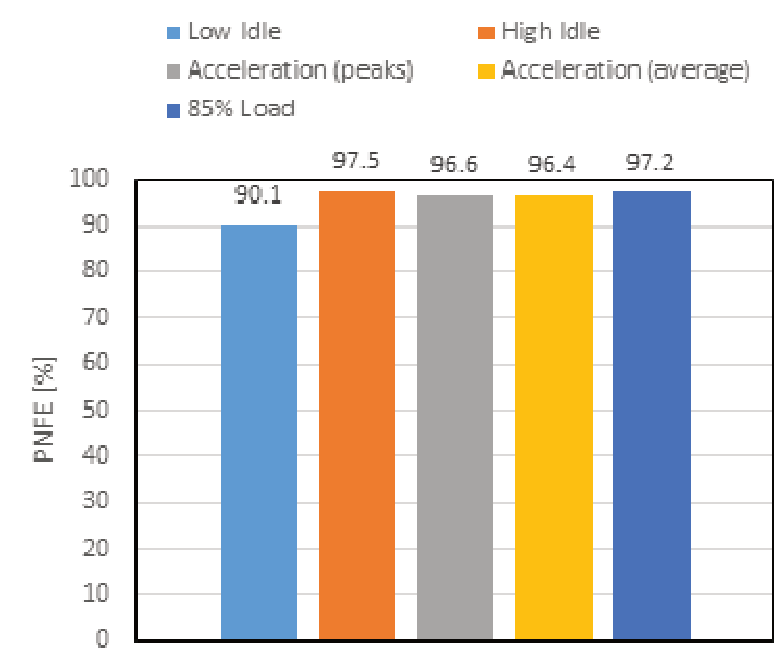

Fig. 2. PNFE as a function of engine operating regime

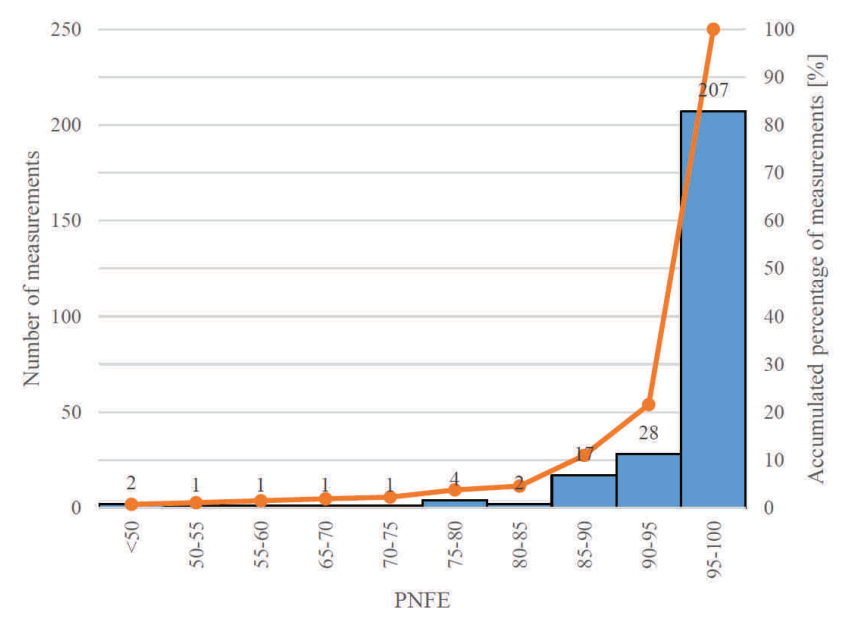

Fig. 3. PNFE histogram

As can be seen from Figure 3, all the results where PNFE values lower than $95 \%$ were measured comprise approximately $20 \%$ only of the total measurements and most probably are the result of various experimental uncertainties. It is important to note that PNFE values higher than $98 \%$ were obtained in $2 / 3$ of the total measurement cases.

An analysis of buses fuel economy performed in accordance with the explained above methodology showed that fuel economy deterioration due to DPF retrofit is lower than frequently mentioned: 0.6 and 1.8 percent only for urban and intercity buses, respectively. A careful analysis of lubricant oil quality and maintenance events during the pilot test does reveal any influence of DPF retrofit on buses maintenance routine. Of course, at some moment filters cleaning due to ash accumulation will be required. Based on the gained values of backpressure during 12 months of the pilot test (did not exceed 75 mbar), we may estimate a frequency of filter cleaning as 2-2.5 years in average. It is clear that an exact need in DPF cleaning should be identified based on backpressure monitoring results.

Based on the success of the pilot test, the government of Israel has decided to invest 6 million USD in 2017 to retrofit of DPFs in heavy-duty diesel vehicles in Haifa region and in garbage trucks - nationwide. From August 2017, a 
use of garbage trucks that do not meet at least Euro IV requirements will be forbidden. An appropriate legislative environment and retrofitting infrastructure are developed. To make the process of retrofitting clear for vehicle owners, a detailed instruction on DPF installation procedure was published by the Israeli Ministry of Transportation. The successful pilot also triggered a decision on Low Emission Zones (LEZ) formation in Israel with the first LEZ to be opened in Haifa (the whole city).

\section{Conclusions}

A pilot test demonstrating feasibility of DPF retrofit in heavy-duty vehicles is necessary as a pre-requisite of the successful retrofit program. Development of the public and governmental awareness to importance of DPF retrofit as an efficient and quick way of air pollution reduction is

\section{Bibliography}

[1] TARTAKOVSKY, L., GUTMAN, M., MOSYAK, A. Energy efficiency of road vehicles - trends and challenges. Chapter 3 in the edited collection "Energy efficiency: methods, limitations and challenges", Emmanuel F. Santos Cavalcanti and Marcos Ribeiro Barbosa (editors). Nova Science Publishers. 2012. 63-90.

[2] DOCKERY, D.W., POPE, C.A., XU, X. et al. An association between air pollution and mortality in six US cities. $N$. Engl. J. Med. 1993, 329, 1753-1759.

[3] POPE III, C., DOCKERY, D. Health effects of fine particulate air pollution: lines that connect. J. Air Waste Manage. Assoc. 2006, 56, 709-742.

[4] International Agency for Research on Cancer, IARC, 2012. Diesel engine exhaust carcinogenic. Press Release No 213, IARC, WHO, www.iarc.fr/en/media-centre/pr/2012/pdfs/ pr213_E.pdf.

[5] SLEZAKOVA, K., MORAIS, S., PEREIRA, M. Atmospheric nanoparticles and their impacts on public health. In: Rodrigues-Morales, A. (Ed.), Current Topics in Public Health. INTECH, 2013, 503-529.

[6] KNIBBS, L.D., COLE E HUNTER, T., MORAWSKA, L. A review of commuter exposure to ultrafine particles and its health effects. Atmos. Environ. 2011, 45, 2611-2622.

\footnotetext{
Leonid Tartakovsky, DEng. - Faculty of Mechanical Engineering, Technion - Israel Institute of Technology, Haifa, Israel.

e-mail:Tartak@technion.ac.il
}

required. This can be done through scientific conferences, meetings with stakeholders and any other possible ways.

Air quality monitoring that includes measurement of black carbon or/and particle number concentrations is necessary to evaluate influence of DPF retrofit and other emissions reduction measures on air pollution. Another important factor affecting the overall success of any retrofit or another emissions mitigation program is an effective roadworthiness program. The latter must include PNC diagnostics, because standard opacity control technologies are not effective anymore in diagnostics of DPF-equipped vehicles.

\section{Acknowledgements}

A financial support of the bus operator Egged is gratefully acknowledged. The authors are grateful to the Israeli Ministry of Environmental Protection for support and fruitful cooperation.
[7] HOET, P.H.M., BRÜSKE-HOHLFELD, I., SALATA, O.V. Nanoparticles - known and unknown health risks. J. Nanobiotechnology. 2004, 2, 12.

[8] MAYER, A., CZERWINSKI, J., MATTER, U. et al. VERT: diesel nano-particulate emissions: properties and reduction strategies. SAE Technical Paper. 1998, 980539.

[9] BOUDART, J., FIGLIOZZI, M. Key variables affecting decisions of bus replacement age and total costs. Transp. Res. Rec. J. Transp. Res. Board. 2012, 2274, 109-113.

[10] MAYER, A. (ed.) Particle filter retrofit for all diesel engines. Expert Verlag. 2008.

[11] TARTAKOVSKY, L., BAIBIKOV, V., COMTE, P. et al. Ultrafine particle emissions by in-use diesel buses of various generations at low-load regimes. Atmos. Environ. 2015, 107, 273-280.

[12] COOPER, B.J., JUNG, H.J., THOSS, J.E. US Patent US4902487. 1990.

[13] ALlANSSON, R., BLAKEMAN, P.G., COOPER, B.J. et al. The use of the continuously regenerating trap (CRTTM) to control particulate emissions: minimising the impact of sulfur poisoning. SAE Technical Paper. 2002, 2002-011271.

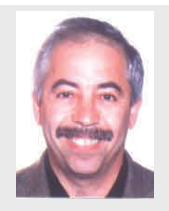

Rafael Fleischman - Faculty of Mechanical Engineering, Technion - Israel Institute of Technology, Haifa, Israel. 